\title{
Influence of the area of the lateral window upon the radiological parameters and implant success in patients with direct sinus lift after 5-12 years of follow-up
}

\author{
Javier Romero-Millán ${ }^{1}$, Javier Aizcorbe-Vicente ${ }^{1}$, David Soto-Peñaloza ${ }^{1}$, Miguel Peñarrocha-Diago ${ }^{2}$, \\ María Peñarrocha-Diago ${ }^{2}$, David Peñarrocha-Oltra ${ }^{2}$
}

${ }^{1}$ DDS, Master in Oral Surgery and Implantology, Faculty of Medicine and Odontology, University of Valencia, Valencia, Spain; ${ }^{2}$ Department of Oral Surgery, Faculty of Medicine and Odontology, University of Valencia, Researcher of the IDIBELL Institute, Barcelona, Spain

Contributions: (I) Conception and design: J Romero-Millán, M Peñarrocha-Diago, D Peñarrocha-Oltra; (II) Administrative support: M PeñarrochaDiago; (III) Provision of study materials or patients: M Peñarrocha-Diago; (IV) Collection and assembly of data: J Romero-Millán, J AizcorbeVicente, D Soto-Peñaloza; (V) Data analysis and interpretation: J Romero-Millán, M Peñarrocha-Diago, D Peñarrocha-Oltra; (VI) Manuscript writing: All authors; (VII) Final approval of manuscript: All authors.

Correspondence to: Dr. David Peñarrocha-Oltra. Clínicas Odontológicas, Gascó Oliag 1, 46021- Valencia, Spain. Email: david.penarrocha@uv.es.

Background: The present study in patients with direct sinus lift and simultaneous or delayed implant placement was carried out to relate the dimensions of the lateral window to sinus augmentation, marginal bone loss, and implant success and survival after a minimum follow-up period of 5 years.

Methods: A retrospective cohort study was carried out in a university clinic. Selection was made of patients treated with implants in the posterior maxillary area in the period 2005-2011. The patients were distributed into two groups according to residual bone height and the consequent variation in size of the lateral window: (I) direct sinus lift with simultaneous implant placement (bone height $\geq 4 \mathrm{~mm}$ ); and (II) direct sinus lift with delayed implant placement (bone height $4-6 \mathrm{~mm}$ ). The area of the lateral window was analyzed and related to the sinus augmentation achieved, marginal bone loss, and implant success and survival after a minimum follow-up period of 5 years after prosthetic loading.

Results: A total of 110 patients with 219 implants were included in the study. The mean duration of follow-up was $7.0 \pm 1.9$ years (range, 5-12 years). The area of the lateral window was $172.7 \pm 82.6 \mathrm{~mm}^{2}$ in group 1 versus $206.9 \pm 112.5 \mathrm{~mm}^{2}$ in group 2 . There were no statistically significant differences between the two groups. Marginal bone loss and implant success and survival were very similar in both groups, with no significant differences between them. The greatest reabsorption of the bone graft occurred during the first 12 months, though constant reabsorption of lesser intensity was observed for up to 5 years. Stabilization of the graft material was recorded from 5 years of follow-up. The area of the lateral window did not influence any of the analyzed parameters (marginal bone loss, sinus augmentation achieved, success and survival).

Conclusions: The dimensions of the lateral window do not influence the obtainment of greater bone gain, the marginal bone loss, or implant success and survival.

Keywords: Sinus lift; lateral window; marginal bone loss; implant success

Received: 21 April 2021; Accepted: 26 September 2021; Published: 10 December 2021.

doi: 10.21037/fomm-21-52

View this article at: https://dx.doi.org/10.21037/fomm-21-52 


\section{Introduction}

Direct sinus lift is one of the most widely used surgical procedures for rehabilitation of the atrophic posterior maxilla with dental implants (1). A number of aspects of this surgical technique have been widely analyzed, including graft materials, ultrasound techniques, immediate implant placement, and complications and their management (2). The first step in direct sinus lift is the design of the antrostomy. However, the influence of the size of the bone window in relation to parameters such as the bone height gained, marginal bone loss and implant success and survival has not been studied over the middle and long term.

Since Wallace et al. (3) initially described the ideal size of the lateral window with a width of $20 \mathrm{~mm}$ and a height of $15 \mathrm{~mm}$, there has been much controversy as to whether the size of the window could affect the outcome of the procedure. The main focus of discussion is the supposed osteogenic capacity that would be obtained by preserving a greater amount of bone and limiting the size of the window. The mentioned authors (3) indicated that a decrease in the dimensions afforded advantages such as improved healing of the bone graft. Baldini et al. (4) compared two sizes of window $(6 \mathrm{~mm} \times 6 \mathrm{~mm}$ versus $10 \mathrm{~mm} \times 8 \mathrm{~mm})$ and concluded that a decrease in window dimensions did not affect the safety of the surgical procedure. They observed no statistically significant differences between the two groups in the sinus augmentation achieved, though the patients experienced greater postoperative discomfort when the window was larger. Yu et al. (5) analyzed the creation of two small windows versus a single window. No significant differences were noted in bone level changes and radiographic endo-sinus bone gain at baseline and one year after surgery. The authors recorded greater connective tissue invagination when performing a single window of greater size. Similar results were reported by Peleg et al. (6) and Avila-Ortiz et al. (7), evidencing poorer maturation and consolidation of the graft when the dimensions of the window were larger. Recent nonclinical evidence based on histomorphometric analyses indicates that direct sinus lift with different window sizes results in similar bone neoformation values in the zone of the antrostomy and in elevation of the maxillary sinus (8). In view of the above, and due to the few longitudinal clinical studies involving periods beyond 24 months, together with the disparity of results reported in the literature, we decided to carry out a retrospective cohort study to analyze the influence of the size of the lateral window in relation to parameters such as the sinus augmentation achieved, marginal bone loss, and the success and survival of dental implants placed simultaneously or delayed with respect to direct sinus lift, with a minimum follow-up period of 5 years.

We present the following article in accordance with the STROBE reporting checklist (available at https://fomm. amegroups.com/article/view/10.21037/fomm-21-52/rc).

\section{Methods}

\section{Study design}

A retrospective cohort study was carried out, involving a minimum follow-up period of 5 years. We selected all consecutive patients subjected to dental implant rehabilitation in the posterior maxilla (from first premolar to second molar) in the Oral Surgery Unit (University of Valencia, Valencia, Spain) between 2005 and 2011. The study was carried out in abidance with the Declaration of Helsinki (as revised in 2013) referred to research in humans, and was approved by the Ethics Committee for Human Research of the University of Valencia (Ref. H1410262226693). All patients gave written informed consent prior to inclusion in the study.

\section{Study population}

We included patients $\geq 18$ years of age, subjected to direct sinus lift with the placement of dental implants either simultaneously or on a delayed basis. All patients were healthy, without organic, biochemical or psychiatric disease (ASA I) or patient with moderate systemic disease, for example diabetes or well-controlled high blood pressure, without impact on daily activity (ASA II). Patients without a radiographic exploration (panoramic and periapical radiographs) at each of the control visits were excluded, as were those failing to report to the scheduled control visits or with a follow-up period of less than 5 years.

According to the residual bone height, the dental implants were placed simultaneously or delayed with respect to direct sinus lift (9). In this respect, the study cohort was divided into two groups:

- Group 1: Patients presenting bone height $\geq 4-6 \mathrm{~mm}$ with implants placed simultaneous to the direct sinus lift procedure.

- Group 2: Patients presenting bone height $<4 \mathrm{~mm}$ and subjected to direct sinus lift with delayed placement of the implants after 6 months of bone healing. 

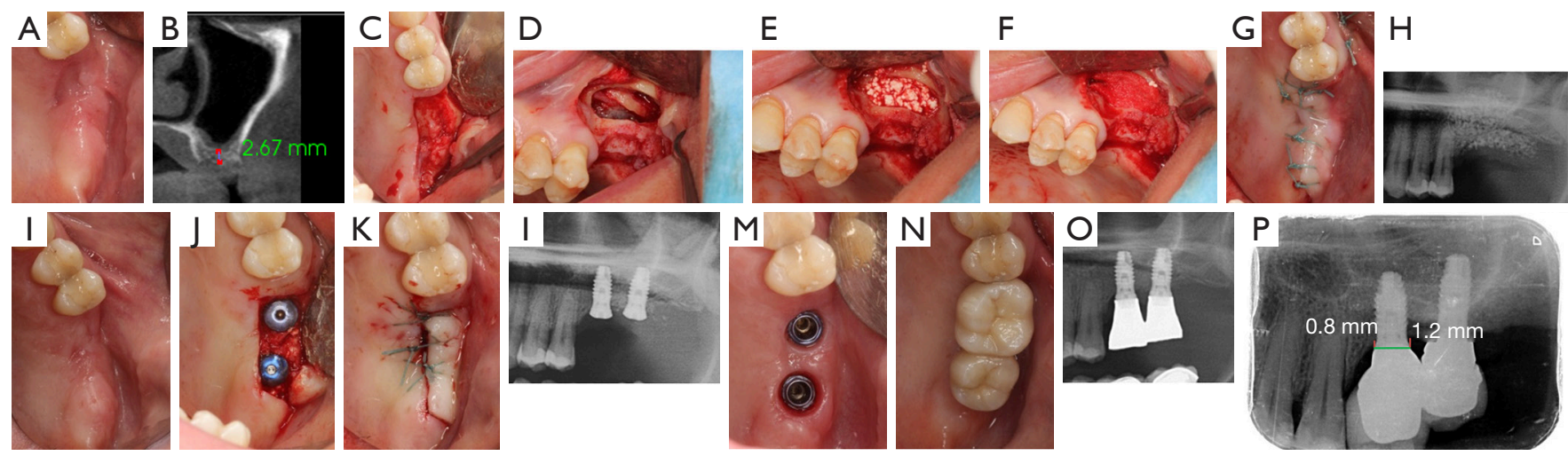

Figure 1 Clinical and radiological images of a patient who underwent a sinus lift with delayed implant placement. (A) Preoperative intraoral view. (B) Tomographic view showing the degree of bone reabsorption. (C) Elevation of the full-thickness flap. (D) Creation of the lateral window and elevation of the Schneiderian membrane. (E) Filling of the sinus cavity with the graft material. (F) Placement of the collagen membrane in the antrostomy. (G) Suturing of the flap. (H) Panoramic radiographic view after sinus lift. (I) Preoperative view after 6 months of graft healing. (J) Occlusal view of implant placement. (K) Suturing of the flap. (L) Panoramic radiographic view after implant placement. (M) Healed mucosa after the osseointegration period. (N) Occlusal view of the positioned prosthesis. (O) Panoramic radiographic view after placement of the prosthesis. (P) Periapical radiographic view after 5 years of follow-up; note the measurement of bone loss.

\section{Surgical procedure}

All the operations were carried out by the same surgeon (MPD) in the operating room under local anesthesia with $4 \%$ articaine and 1:100,000 adrenaline (Inibsa ${ }^{\circledR}$, Lliça de Vall, Barcelona, Spain). The implants used in this study were Phibo ${ }^{\circledR}$ TSA implants (Phibo Dental Solutions, S.L., Sentmenat, Barcelona, Spain). The direct sinus lift procedure was the same in both groups. The window ostectomy was started with a round tungsten carbide drill and was completed with ultrasound (Surgysonic ${ }^{\circledR}$, Esacrom, Imola, Italy). At this point we measured the size of the lateral window using a millimetered periodontal probe. Detachment of the Schneiderian membrane was carried out with a combination of ultrasound instruments and manual curettes. In all cases we used $\beta$-tricalcium phosphate $\left(\mathrm{KeraOs}^{\circledR}\right.$, Keramat S.L.U., Ames, A Coruña, Spain) as sole graft material, and the lateral window was covered with a reabsorbable collagen membrane (Bio-Gide ${ }^{\circledR}$, Geistlich Pharma AG, Wolhusen, Switzerland). The implants were placed following the drilling sequence recommended by the manufacturer, in the same surgical procedure in group 1 and in second surgery after bone healing in group 2 . All the implants were left submerged.

The same postoperative medication was prescribed in all cases: amoxicillin/clavulanic acid (Augmentine ${ }^{\circledR}$, GlaxoSmithKline, S.A., Madrid, Spain) $500 \mathrm{mg} / 8$ hours during 7 days, ibuprofen (Bexistar ${ }^{\circledR}$, Laboratorio Barcino,
Barcelona, Spain) $600 \mathrm{mg} / 8$ hours during three days, and $0.12 \%$ chlorhexidine rinses $\left(\mathrm{GUM}^{\circledR}\right.$, John O. Butler Co., Chicago, IL, USA) three times a day during 7 days.

The healing caps were placed in a second surgical procedure after a 6-month healing period in all cases. The time to manufacture of the prosthesis was approximately four weeks (Figure 1).

\section{Follow-up and maintenance}

All the patients underwent annual control visits in which professional cleaning was made. At the time of the study, the patients had been under follow-up for at least 5 years. Two timepoints were used for the statistical calculations: 5-year follow-up (available in all cases) and maximum follow-up (which was heterogeneous, ranging from 5-12 years). For maximum follow-up, the last available data for each case were used for the analysis.

\section{Data collection}

\section{Personal data}

We recorded the age of the patients at the time of surgery, systemic disease, smoking status (non-smoker, $<10$ cigarettes a day, 11-20 cigarettes a day, >20 cigarettes a day) (10), alcohol consumption (the latter being defined as $>10 \mathrm{~g}$ alcohol a day, equivalent to $250 \mathrm{~mL}$ of beer) (11) and 


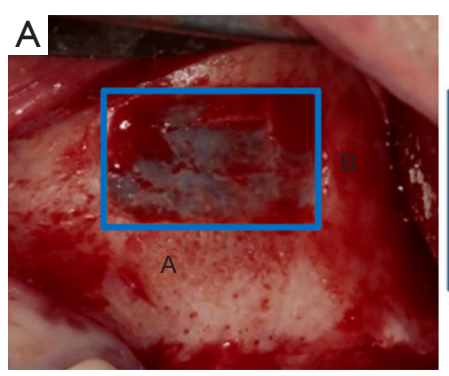

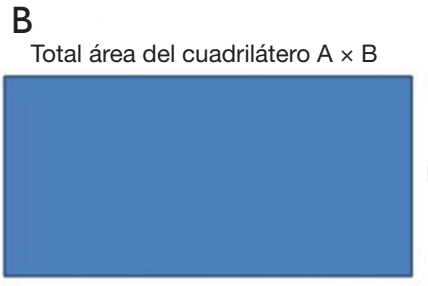

A
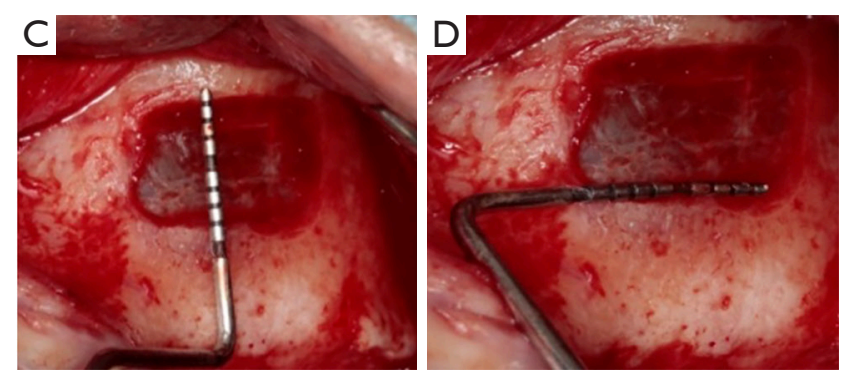

Figure 2 Measurement of the height and width of the lateral window using a periodontal probe to calculate the area. (A) Lateral window simulation as a quadrangle. (B) Representative view of the area of the quadrangle. (C) Measurement of the height of the lateral window using the CP-15 probe. (D) Measurement of the width of the lateral window.

presence of sinus septa.

\section{Area of the lateral window}

At the time of surgery we measured the dimensions of the lateral window. To obtain the area, we measured both the width and the height using a millimetered probe. In all cases, and independently of its form, the lateral window was regarded as a quadrangle, as indicated by Avila-Ortiz et al. (7), and its area was calculated (in $\mathrm{mm}^{2}$ ) using a simple mathematical formula (Figure 2).

\section{Condition of the sinus membrane}

Perforation of the Schneiderian membrane during preparation of the lateral window or during detachment was recorded, and the size was measured with a millimetered periodontal probe.

\section{Sinus augmentation achieved}

We calculated the height of the bone from the panoramic radiographs (Orthopantomograph ${ }^{\circledR}$ OP 100, Instrumentarium Imaging, Tuusula, Finland), as described by Peñarrocha et al. (12), using the Cliniview ${ }^{\circledR}$ version 5.1 application (Instrumentarium Imaging, Tuusula, Finland). To perform the measurements, we first calibrated the panoramic radiographs: based on the length of the implant in the case of placement simultaneous to sinus lift, and using a $5-\mathrm{mm}$ steel ball within a radiological resin splint in the case of delayed placement. We calculated the height in millimeters from the inferior sinus cortical layer to the upper limit of the graft material. In the case of delayed implant placement, the first measurement of the bone graft was made after surgery in the zone where the implants would later be placed. In those cases where the implants were already placed, the measurements were made at the center of the implant. We performed as many measurements as the number of implants placed (1).

\section{Marginal bone loss}

Marginal bone loss (MBL) was evaluated following the procedure described by Boronat et al. (13). Radiological exploration was carried out with an XMIND intraoral system (Groupe Satelec-Pierre Rolland, Bordeaux, France) and an RVG intraoral digital receptor (Kodak Dental System, Atlanta, GA, USA). To reproduce the patient alignments, a rigid cross-arch bar was used with biteregistration material and a Rinn XCP (Dentsply, Des Plaines, IL, USA) rod and ring were firmly attached to the bar and placed in contact with the $\mathrm{X}$-ray cone. The receptor was held by a slot in the bar. Software-based measurements were made (in $\mathrm{mm}$ ) of marginal bone loss of the implant at the time of loading and at each of the control visits. For measurement purposes, two visible and easily localized reference points were selected at the junction point between the implant and the prosthetic restoration. A straight line was traced joining the two reference points, and was considered to represent zero height. For the determination of bone loss, a perpendicular line was traced mesial and distal to the implant from zero height to contact with the bone. The difference between the value recorded at the time of loading and at each follow-up visit was used to calculate bone loss mesial and distal to the implant (1).

\section{Implant success and survival}

The definition of success was based on the clinical and radiological criteria of Albrektsson et al. (14). Implant survival was considered when the implant was in the mouth and performing its function, regardless of its condition, while failure was considered as the absence of success, and a lost implant was defined as an implant without survival. 
Table 1 Data compilation: patient age and gender, systemic disease, smoking, alcohol and presence sinus septa

\begin{tabular}{|c|c|c|c|c|c|c|c|c|c|c|}
\hline & Age & \multicolumn{2}{|c|}{ Gender } & $\begin{array}{l}\text { Systemic } \\
\text { disease }\end{array}$ & \multicolumn{4}{|c|}{ Smoking } & Alcohol & $\begin{array}{l}\text { Sinus } \\
\text { septa }\end{array}$ \\
\hline Group 1 & $54.5 \pm 10.6$ & 19 & 43 & 18 & 42 & 11 & 5 & 4 & 17 & 10 \\
\hline Group 2 & $55.0 \pm 9.0$ & 17 & 31 & 9 & 28 & 16 & 3 & 1 & 14 & 2 \\
\hline
\end{tabular}

\section{Statistical analysis}

A descriptive analysis was made, with calculation of the mean, standard deviation (SD), minimum, maximum and median for the variables area of the lateral window, bone loss and sinus augmentation achieved, as well as the success and survival rates. Given the important sample size, the analysis approach is parametric through linear models. The relationship between bone loss (or height gained) and the group or area of the window over the global followup period or at a specific timepoint was evaluated using generalized estimating equations (GEE). The main effects and interactions were contrasted with the Wald chi-square statistic. This methodology controls for the hierarchical structure of the data and the consequent intra-subject and intra-sinus correlation. The same types of models (GEE logistic regressions) were used for the analysis of success and survival. The analysis of survival was adjusted for potential effect modifiers (smoking, alcohol), thereby controlling the risk of confounding bias. The log-rank test was used to compare the Kaplan-Meier survival curves according to the group involved. The level of significance was established as $5 \%(\mathrm{alfa}=0.05)$. A total of 219 implants resulted in a statistical power of $91 \%$ in detecting a medium-small effect size $(\mathrm{f}=0.2)$ in the differences in bone loss between groups, assuming a $95 \%$ confidence level. On assuming a moderate intra-subject correlation $(\rho=0.5)$, the effective power was $75 \%$.

\section{Results}

We evaluated a total of 150 patients: 76 subjected to direct sinus lift with simultaneous implant placement (group 1), and 74 subjected to direct sinus lift with delayed implant placement (group 2). A total of 40 patients were excluded: 11 due to the lack of a full radiological study and 29 because of failure to report to the periodic control visits.

The final sample thus consisted of 110 patients with 219 implants. Group 1 comprised 62 patients with 113 implants and 75 sinus lift procedures. Group 2 in turn comprised 48 patients with 106 implants and 56 sinus lift procedures. There were no statistically significant differences between the groups $(P>0.05)$. The mean duration of follow-up was $7.0 \pm 1.9$ years (range, $5-12$ years). The mean age was $54.1 \pm 10.7$ years. With regard to gender distribution, females predominated in both groups, though statistical significance was not reached $\left(\mathrm{P}=0.072, \mathrm{Chi}^{2}\right)$. No significant differences were observed between the groups in terms of age $(\mathrm{P}=0.531)$. Twenty-seven patients reported having a mild systemic disease (diabetes, hypertension or hypercholesterolemia). No differences were found between the groups $\left(\mathrm{P}=0.240, \mathrm{Chi}^{2}\right)$, nor did their presence influence implant survival $\left(\mathrm{P}=0.116, \mathrm{Chi}^{2}\right.$ Wald $)$. With regard to smoking, 11 and 16 patients smoked $<10$ cigarettes a day in groups 1 and 2, respectively. Five patients claimed to smoke $>20$ cigarettes a day (four in group 1 and one in group 2). Thirty-seven patients reported alcohol intake (17 in group 1 and 14 in group 2). Comparison of the distribution of smoking and alcohol intake between the groups showed no significant differences $\left(\mathrm{P}>0.05, \mathrm{Chi}^{2}\right)$. When relating implant survival to smoking, a greater number of failures were observed in smokers, although it was not statistically significant $\left(\mathrm{P}=0.882\right.$, $^{2}{ }^{2}$ Wald). Neither was a relationship found with the success of the implants $\left(\mathrm{P}=0.486, \mathrm{Chi}^{2}\right.$ Wald).

The patients' alcohol habit was also not related to a lower survival $\left(\mathrm{P}=0.933\right.$, $\mathrm{Chi}^{2}$ Wald $)$ or a lower success $\left(\mathrm{P}=0.589, \mathrm{Chi}^{2}\right.$ Wald $)$. Of all the patients included in the study, 12 had bony septa. The majority belonged to group 1, which determined a significant difference in the proportion with respect to group $2\left(\mathrm{P}=0.006, \mathrm{Chi}^{2}\right)$. No statistically significant relationship was found between the presence of septa and lower survival $\left(\mathrm{P}=0.422, \mathrm{Chi}^{2}\right.$ Wald $)$ and success $\left(\mathrm{P}=0.734\right.$, Chi $^{2}$ Wald $)$ (Table 1).

\section{Area of the lateral window}

The mean area of the lateral window was $187.6 \pm 97.8 \mathrm{~mm}^{2}$. The mean area in group 1 was $172.7 \pm 82.6 \mathrm{~mm}^{2}$ versus $206.9 \pm 112.5 \mathrm{~mm}^{2}$ in group 2-the difference between groups being nonsignificant $(\mathrm{P}=0.069, t$-test $)$. 


\section{Condition of the sinus membrane}

Perforation of the membrane occurred in $16 \%$ of the cases, and was seen to be more frequent in the group subjected to direct sinus lift with simultaneous placement of the implants. Overall, the mean size of the perforation of the Schneiderian membrane was $4.9 \pm 2.3 \mathrm{~mm}$. The mean size was $4.6 \pm 1.7$ in group 1 and $5.3 \pm 2.8 \mathrm{~mm}$ in group 2 . The difference was not statistically significant $(\mathrm{P}=0.500)$. Furthermore, the size of the perforation did not influence the success rate or the survival rate $(\mathrm{P}=0.198)$. No statistically significant differences were recorded on comparing the number of perforations between the groups $\left(\mathrm{P}=0.638, \mathrm{Chi}^{2}\right)$. The patients with perforation of the membrane did not present significantly more failures $\left(\mathrm{P}=0.182, \mathrm{Chi}^{2}\right)$, and implant success was likewise not influenced by perforation $\left(\mathrm{P}=0.681, \mathrm{Chi}^{2}\right)$.

\section{Sinus augmentation achieved}

The mean sinus augmentation achieved was greater in group 2 with delayed implant placement $(10.1 \pm 3.3 \mathrm{~mm})$ than in group 1 with simultaneous implant placement $(8.2 \pm 2.2 \mathrm{~mm})$. The difference was statistically significant at all the follow-up timepoints $(\mathrm{P}<0.001)$. The sinus augmentation achieved in each of the groups throughout study follow-up is reported in Table 2.

On analyzing the sinus augmentation achieved over time, a significant decrease was recorded in both groups $(\mathrm{P}<0.001)$.

Table 2 Sinus augmentation achieved at each timepoint over follow-up

\begin{tabular}{ccccc}
\hline & \multicolumn{4}{c}{ Bone gain $(\mathrm{mm})$} \\
\cline { 2 - 5 } & Sinus lift & 12 months & 5 years & Maximum follow-up \\
\hline Group 1 & $8.2 \pm 2.2$ & $7.2 \pm 2.0$ & $7.0 \pm 2.0$ & $7.0 \pm 2.0$ \\
Group 2 & $10.1 \pm 3.3$ & $9.0 \pm 2.8$ & $8.7 \pm 2.7$ & $8.7 \pm 2.7$ \\
\hline
\end{tabular}

The greatest reabsorption of the graft occurred during the first 12 months, though from 5 years of follow-up no further statistically significant reabsorptions were observed $(\mathrm{P}=0.458$ and $\mathrm{P}=0.086$, groups 1 and 2, respectively). This evidences stabilization of the graft. We likewise recorded differences in height gained according to the group involved $(\mathrm{P}<0.001)$ : group 2 always presented a greater mean height than group 1 - the difference being statistically significant at all timepoints $(\mathrm{P}<0.001)$. Lastly, the evolution of the sinus augmentation achieved was similar over time in both groups $(\mathrm{P}=0.630)$ (Table 1). On relating the sinus augmentation achieved to the size of the window, no statistically significant association was observed in either group. A greater size of the lateral window did not influence the obtainment of greater height of the bone graft at any of the study timepoints $(\mathrm{P}>0.001)$.

\section{Marginal bone loss}

The mean marginal bone loss was $0.4 \pm 0.4 \mathrm{~mm}$ for both groups after 12 months of prosthetic loading. At 5 years, the marginal bone loss was $0.8 \pm 0.6 \mathrm{~mm}$ and $0.7 \pm 0.6 \mathrm{~mm}$ in groups 1 and 2, respectively. After the maximum period of follow-up, the marginal bone loss was $0.9 \pm 0.6$ and $0.8 \pm 0.6 \mathrm{~mm}$ in groups 1 and 2 , respectively (Table 3 ). There were no statistically significant differences between the groups at any of the analyzed timepoints. On examining the relationship between bone loss and the size of the lateral window, no statistically significant association was observed in either of the two groups at 12 months $(\mathrm{P}=0.788), 5$ years $(\mathrm{P}=0.255)$ or over maximum follow-up $(\mathrm{P}=0.123)$.

\section{Implant success and survival}

The success and survival rates, and the number of implants lost in each of the groups are described in Table 4. The success rate of the implants in group 1 was $93.8 \%, 93.8 \%$

Table 3 Bone loss

\begin{tabular}{|c|c|c|c|c|c|c|c|c|c|}
\hline & \multicolumn{9}{|c|}{ Bone loss (mm) } \\
\hline & Mesial & Distal & Mean & Mesial & Distal & Mean & Mesial & Distal & Mean \\
\hline Group 1 & $0.4 \pm 0.5$ & $0.4 \pm 0.5$ & $0.4 \pm 0.4$ & $0.8 \pm 0.6$ & $0.8 \pm 0.7$ & $0.8 \pm 0.6$ & $0.9 \pm 0.7$ & $0.9 \pm 0.7$ & $0.9 \pm 0.6$ \\
\hline Group 2 & $0.4 \pm 0.4$ & $0.4 \pm 0.4$ & $0.4 \pm 0.4$ & $0.7 \pm 0.6$ & $0.7 \pm 0.6$ & $0.7 \pm 0.6$ & $0.8 \pm 0.7$ & $0.8 \pm 0.7$ & $0.8 \pm 0.6$ \\
\hline
\end{tabular}


Table 4 Implant success and survival at each timepoint over follow-up

\begin{tabular}{|c|c|c|c|c|c|c|c|c|}
\hline & \multicolumn{3}{|c|}{$\%$ Success } & \multicolumn{3}{|c|}{ \% Survival } & \multicolumn{2}{|c|}{ Implants lost } \\
\hline Group 1 & 93.8 & 93.8 & 88 & 94.7 & 94.7 & 94.7 & 6 & 0 \\
\hline Group 2 & 98.1 & 91.5 & 90.1 & 98.1 & 93.4 & 93.4 & 2 & 5 \\
\hline$P$ value & \multicolumn{3}{|c|}{ 0.297, Log-rank test } & \multicolumn{3}{|c|}{0.405 , Log-rank test } & \multicolumn{2}{|c|}{ _- } \\
\hline
\end{tabular}

and $88 \%$ at one year, 5 years and at maximum follow-up, respectively. The success rate of the implants in group 2 was $98.1 \%, 91.5 \%$ and $90.1 \%$ at one year, 5 years and at maximum follow-up, respectively. In turn, the implant survival rate in group 1 was found to be $94.7 \%$ for all the periods of follow-up, with no losses being recorded after the first year of loading. In group 2 the survival rate was $98.1 \%$, $93.4 \%$ and $93.4 \%$ at one year, 5 years and at maximum follow-up, respectively. We recorded no statistically significant differences in terms of implant success or survival between the groups at any of the timepoints considered.

On relating these data to the size of the lateral window, no statistically significant influence was observed in relation to either implant survival $(\mathrm{P}=0.297$, log-rank test) or success $(\mathrm{P}=0.405, \log$-rank test).

Smoking and alcohol were related to implant survival using generalized estimating equations (GEE). Implant failure was found to be more frequent among smokers, though statistical significance was not reached $(\mathrm{P}=0.882$, $\left.\mathrm{Chi}^{2}\right)$. Similar results were obtained in relation to implant success $\left(\mathrm{P}=0.486, \mathrm{Chi}^{2}\right)$. On the other hand, alcohol intake was not related to lesser implant survival $\left(\mathrm{P}=0.933, \mathrm{Chi}^{2}\right)$ or success $\left(\mathrm{P}=0.589, \mathrm{Chi}^{2}\right)$.

\section{Discussion}

In recent years a number of studies have underscored the advantages of a small lateral window-the main argument being the greater osteogenic potential achieved by preserving as much lateral wall of the sinus as possible (5,15-17). Some authors have also reported that a reduction of the size of the lateral window results in less postoperative pain (18), and that patients show a preference for this type of minimally invasive technique (4). Another advantage is a reduction of the amount of connective tissue invaginated within the graft, even when a collagen membrane has been used to cover the antrostomy (19-21). As a drawback, the technical difficulties are greater, and good surgical skill is required to adequately manage the intraoperative complications (e.g., perforation of the membrane, bleeding) (4).

When we analyzed the presence of any systemic disease (diabetes, hypertension, hypercholesterolemia) in the patients at the time of surgery, no statistically significant differences were found between the groups. Most of the articles do not include this variable. Johansson et al. (22) divided the patients according to the ASA 1 or 2 scale. When analyzing all medically compromised patients, ASA 2 found that all patients in the sinus lift group lost one or more implants. However, the number of ASA 2 patients was so small that a statistical relationship between the ASA index and implant failure could not be established. Wannfors et al. (23) also did not find a higher risk of failure in ASA 2 patients.

Regarding the habits of the patients included in the study, we observed that higher tobacco consumption had a greater distribution in implant failure, although without statistical significance. Similar results have been reported by a systematic review (24) including 8 articles (three prospective and 5 retrospective studies). On jointly evaluating the 8 studies, smoking was associated to greater implant failure. However, on only considering the three prospective studies, no differences in implant success rate were observed between smokers and non-smokers. Alcohol consumption had no impact upon the study variables. However, it should be noted that alcohol can affect the bone graft, since patients with alcohol abuse present a combination of factors such as malnutrition, poor oral hygiene and failure to follow recommendations (25). Such patients must be closely evaluated for concomitant use of other substances, or possible addictions.

Anatomical variations such as the antral septa increase the risk of producing perforations of the sinus membrane (26), this will force to modify the design of the lateral window (27). It is advisable to make two windows, on both sides of the septum or to make one in the shape of a $W$. In a review of the literature published by Maestre et al. (28) established that between $13 \%$ and $35.3 \%$ of the maxillary sinuses have antral 
septa and that these are not a contraindication to perform sinus elevation. In our study, septa were present in $10.9 \%$ of the patients, this is slightly lower than those described in the literature review.

In calculating the area, we assumed a quadrangle, as indicated by Avila-Ortiz et al. (7). The resulting mean area of the window $\left(187.6 \pm 97.8 \mathrm{~mm}^{2}\right)$ was greater than in other previous studies in which smaller size windows were made $(4,5)$. Nevertheless, the size was similar to that of the ideal window proposed by Wallace et al. (3). We recorded a mean marginal bone loss of $0.9 \pm 0.6 \mathrm{~mm}$ in group 1 and of $0.8 \pm$ $0.6 \mathrm{~mm}$ in group 2 at the last follow-up visit. These results are very similar to those obtained by Felice et al. (29) after one year of follow-up. The sinus augmentation achieved was determined from calibrated panoramic radiographs. In order to correct for possible magnification of the images, we used the known length of the implant or a $5-\mathrm{mm}$ steel ball within a radiological resin splint as reference. The utilization of panoramic radiographic techniques could be regarded as a limitation, though they have been validated for studies of this kind $(30,31)$. The sinus augmentation achieved decreased significantly in the first 12 months, but was seen to stabilize after 5 years of prosthetic loading. Very similar results were reported in the study published by Zijderveld et al. (32), where the decrease was mainly observed after 1.5 years, followed by practically stable conditions from 5 years of follow-up. At maximum follow-up, the mean success rate in both groups was $89.05 \%$, with a survival rate of $94.05 \%$. Very similar findings have been published by most of the studies analyzed in a systematic review (2).

We recorded a $16 \%$ incidence of perforations of the sinus membrane, with a mean size of $4.9 \mathrm{~mm}$. The data found in the literature are heterogeneous in this regard. Some authors have established a correlation between perforations of the membrane and the implant survival rate $(33,34)$, while others have found no evidence of such a correlation (35). In our study, neither the presence nor the size of the perforation influenced implant success or survival. This may be due to the small size of the perforations, for as indicated by Froum et al. (36), perforation of the Schneiderian membrane does not affect implant survival or the formation of vital bone, provided adequate repair is ensured.

No associations were observed on examining the influence of the size of the window upon the different study parameters (marginal bone loss, sinus augmentation achieved, success and survival). Marginal bone loss has been studied by Yu et al. (5). On comparing a single lateral window of standard size versus two small windows, these authors observed no significant differences in terms of marginal bone loss between the two groups. These results are consistent with our own findingsno significant differences being recorded in relation to the size of the lateral window and marginal bone loss. As regards the influence of the size of the window upon the sinus augmentation achieved, Baldini et al. (4) recorded no significant differences on comparing a $6 \mathrm{~mm} \times 6 \mathrm{~mm}$ window versus a $10 \mathrm{~mm} \times 8 \mathrm{~mm}$ window. Similar results were reported by Lu et al. (37), who observed no significant differences in the height of the graft on comparing sinus windows with a height of $3-5$ versus $6-8 \mathrm{~mm}$. Both of these studies involved a one-year follow-up period. These clinical findings are consistent with the data reported by a histomorphometric study randomly comparing elevation of the maxillary sinus with different anthrostomy sizes, in which no differences in the outcomes of direct sinus lift were seen (8). In the present study, the size of the window had no statistically significant effect upon the sinus augmentation achieved. With regard to implant survival, Lu et al. (37) recorded no significant differences at one year between a small window (height $3-5 \mathrm{~mm}$ ) and a standard window $(6-8 \mathrm{~mm})$. Yu et al. (5), in their study of two miniwindows, observed no differences between groups in relation to implant survival. In the present study, we likewise recorded no significant differences between the two groups.

The present study contributes evidence of clinical interest on a topic that has been little studied to date. Nevertheless, it has a number of limitations, such as the design involved (retrospective study) and the fact that no comparison was made of window size in the same intervention group. On the other hand, mention is required of the efforts made to analyze the covariables and potential effect modifiers recognized in the literature (e.g., smoking and alcohol)—making it possible to minimize and control confounding factors. The results of our study can be extrapolated to patients without relevant systemic disease conditions that require dental implant treatment either simultaneous to direct sinus lift or on a delayed basis. The approach has afforded predictable outcomes over a follow-up period of 5-12 years. Future prospective and controlled trials are indicated in order to further consolidate the results obtained.

\section{Conclusions}

The size of the lateral window in direct sinus lift procedures does not influence marginal bone loss or implant survival or success over a minimum follow-up period of 5 years. The 
sinus augmentation achieved is likewise not influenced by the window size at 5 years.

\section{Acknowledgments}

Funding: The present study was performed with resources of the University of Valencia.

\section{Footnote}

Provenance and Peer Review: This article was commissioned by the Guest Editor (Mario Pérez-Sayáns) for the series "Marginal Bone Loss in Dental Implants: Factors Affecting and How to Prevent It" published in Frontiers of Oral and Maxillofacial Medicine. The article has undergone external peer review.

Reporting Checklist: The authors have completed the STROBE reporting checklist. Available at https://fomm. amegroups.com/article/view/10.21037/fomm-21-52/rc

Data Sharing Statement: Available at https://fomm. amegroups.com/article/view/10.21037/fomm-21-52/dss

Peer Review File: Available at https:/fomm.amegroups.com/ article/view/10.21037/fomm-21-52/prf

Conflicts of Interest: All authors have completed the ICMJE uniform disclosure form (available at https://fomm. amegroups.com/article/view/10.21037/fomm-21-52/coif). The series "Marginal Bone Loss in Dental Implants: Factors Affecting and How to Prevent It" was commissioned by the editorial office without any funding or sponsorship. The authors have no other conflicts of interest to declare.

Ethical Statement: The authors are accountable for all aspects of the work in ensuring that questions related to the accuracy or integrity of any part of the work are appropriately investigated and resolved. The study was carried out in abidance with the Declaration of Helsinki (as revised in 2013) referred to research in humans, and was approved by the local Ethics Committee for Human Research of the University of Valencia (Ref. H1410262226693). All patients gave written informed consent prior to inclusion in the study.

Open Access Statement: This is an Open Access article distributed in accordance with the Creative Commons
Attribution-NonCommercial-NoDerivs 4.0 International License (CC BY-NC-ND 4.0), which permits the noncommercial replication and distribution of the article with the strict proviso that no changes or edits are made and the original work is properly cited (including links to both the formal publication through the relevant DOI and the license). See: https://creativecommons.org/licenses/by-nc-nd/4.0/.

\section{References}

1. Romero-Millán J, Hernández-Alfaro F, Peñarrocha-Diago $\mathrm{M}$, et al. Simultaneous and delayed direct sinus lift versus conventional implants: Retrospective study with 5-years minimum follow-up. Med Oral Patol Oral Cir Bucal 2018;23:e752-60.

2. Pjetursson BE, Tan WC, Zwahlen M, et al. A systematic review of the success of sinus floor elevation and survival of implants inserted in combination with sinus floor elevation. J Clin Periodontol 2008;35:216-40.

3. Wallace SS, Tarnow DP, Froum SJ, et al. Maxillary sinus elevation by lateral window approach: evolution of technology and technique. J Evid Based Dent Pract 2012;12:161-71.

4. Baldini N, D'Elia C, Bianco A, et al. Lateral approach for sinus floor elevation: large versus small bone window - a split-mouth randomized clinical trial. Clin Oral Implants Res 2017;28:974-81.

5. Yu H, Qiu L. A prospective randomized controlled trial of two-window versus solo-window technique by lateral sinus floor elevation in atrophic posterior maxilla: Results from a 1-year observational phase. Clin Implant Dent Relat Res 2017;19:783-92.

6. Peleg M, Garg AK, Misch CM, et al. Maxillary sinus and ridge augmentations using a surface-derived autogenous bone graft. J Oral Maxillofac Surg 2004;62:1535-44.

7. Avila-Ortiz G, Wang HL, Galindo-Moreno P, et al. Influence of lateral window dimensions on vital bone formation following maxillary sinus augmentation. Int J Oral Maxillofac Implants 2012;27:1230-8.

8. Scala A, Viña-Almunia J, Carda C, et al. Sequential healing of the elevated sinus floor with different size of antrostomy: a histomorphometric study in rabbits. Oral Maxillofac Surg 2020;24:403-10.

9. Jensen OT, Shulman LB, Block MS, et al. Report of the Sinus Consensus Conference of 1996. Int J Oral Maxillofac Implants 1998;13 Suppl:11-45.

10. Martorell-Calatayud L, Romero-Millán J, PeñarrochaOltra D, et al. Influence of smoking and oral higiene on 
succes of implants placed after direct sinus lift. Journal of Oral Science \& Rehabilitation. 2015;1:70-5.

11. Galindo-Moreno P, Fauri M, Avila-Ortiz G, et al. Influence of alcohol and tobacco habits on peri-implant marginal bone loss: a prospective study. Clin Oral Implants Res 2005;16:579-86.

12. Peñarrocha-Diago $M$, Peñarrocha-Diago $M$, SanchezRecio C, et al. Osteotomy in direct sinus lift. A comparative study of the rotary technique and ultrasound. Med Oral Patol Oral Cir Bucal 2012;17:e457-61.

13. Boronat A, Peñarrocha M, Carrillo C, et al. Marginal bone loss in dental implants subjected to early loading (6 to 8 weeks postplacement) with a retrospective short-term follow-up. J Oral Maxillofac Surg 2008;66:246-50.

14. Albrektsson T, Zarb G, Worthington P, et al. The longterm efficacy of currently used dental implants: a review and proposed criteria of success. Int J Oral Maxillofac Implants 1986;1:11-25.

15. Jung UW, Hong JY, Lee JS, et al. A hybrid technique for sinus floor elevation in the severely resorbed posterior maxilla. J Periodontal Implant Sci 2010;40:76-85.

16. Pariente L, Dada K, Daas M. Mini-lateral windows for minimally invasive maxillary sinus augmentation: case series of a new technique. Implant Dent 2014;23:371-7.

17. Hong JY, Baek WS, Cha JK, et al. Long-term evaluation of sinus floor elevation using a modified lateral approach in the posterior maxilla. Clin Oral Implants Res 2017;28:946-53.

18. Nickenig HJ, Wichmann M, Zöller JE, et al. 3-D based minimally invasive one-stage lateral sinus elevation - a prospective randomized clinical pilot study with blinded assessment of postoperative visible facial soft tissue volume changes. J Craniomaxillofac Surg 2014;42:890-5.

19. Barone A, Ricci M, Grassi RF, et al. A 6-month histological analysis on maxillary sinus augmentation with and without use of collagen membranes over the osteotomy window: randomized clinical trial. Clin Oral Implants Res 2013;24:1-6.

20. Scala A, Lang NP, Velez JU, et al. Effects of a collagen membrane positioned between augmentation material and the sinus mucosa in the elevation of the maxillary sinus floor. An experimental study in sheep. Clin Oral Implants Res 2016;27:1454-61.

21. Favero V, Lang NP, Canullo L, et al. Sinus floor elevation outcomes following perforation of the Schneiderian membrane. An experimental study in sheep. Clin Oral Implants Res 2016;27:233-40.

22. Johansson B, Wannfors K, Ekenbäck J, et al. Implants and sinus-inlay bone grafts in a 1-stage procedure on severely atrophied maxillae: surgical aspects of a 3-year follow-up study. Int J Oral Maxillofac Implants 1999;14:811-8.

23. Wannfors K, Johansson B, Hallman M, et al. A prospective randomized study of 1- and 2-stage sinus inlay bone grafts: 1-year follow-up. Int J Oral Maxillofac Implants 2000;15:625-32.

24. Chambrone L, Preshaw PM, Ferreira JD, et al. Effects of tobacco smoking on the survival rate of dental implants placed in areas of maxillary sinus floor augmentation: a systematic review. Clin Oral Implants Res 2014;25:408-16.

25. Li J, Wang HL. Common implant-related advanced bone grafting complications: classification, etiology, and management. Implant Dent 2008;17:389-401.

26. Chanavaz M. Maxillary sinus: anatomy, physiology, surgery, and bone grafting related to implantology--eleven years of surgical experience (1979-1990). J Oral Implantol 1990;16:199-209.

27. van den Bergh JP, ten Bruggenkate CM, Disch FJ, et al. Anatomical aspects of sinus floor elevations. Clin Oral Implants Res 2000;11:256-65.

28. Maestre L, Galán S, Rubio M, et al. Maxillary sinus septa: a systematic review. Med Oral Patol Oral Cir Bucal 2010:1;15:383-6.

29. Felice P, Pistilli R, Piattelli M, et al. 1-stage versus 2-stage lateral sinus lift procedures: 1 -year post-loading results of a multicentre randomised controlled trial. Eur J Oral Implantol 2014;7:65-75.

30. Harris D, Buser D, Dula K, et al. E.A.O. guidelines fo the use of diagnostic imaging in implant dentistry. A consensus workshop organized by the European Association for Osseointegration in Trinity College Dublin. Clin Oral Implants Res 2002;13:566-70.

31. Angelopoulos C, Thomas SL, Hechler S, et al. Comparison between digital panoramic radiography and cone-beam computed tomography for the identification of the mandibular canal as part of presurgical dental implant assessment. J Oral Maxillofac Surg 2008;66:2130-5.

32. Zijderveld SA, Schulten EA, Aartman IH, et al. Long-term changes in graft height after maxillary sinus floor elevation with different grafting materials: radiographic evaluation with a minimum follow-up of 4.5 years. Clin Oral Implants Res 2009;20:691-700.

33. Hernández-Alfaro F, Torradeflot MM, Marti C. Prevalence and management of Schneiderian membrane perforations during sinus-lift procedures. Clin Oral Implants Res 2008;19:91-8.

34. Viña-Almunia J, Peñarrocha-Diago M, Peñarrocha- 
Diago M. Influence of perforation of the sinus membrane on the survival rate of implants placed after direct sinus lift. Literature update. Med Oral Patol Oral Cir Bucal 2009;14:E133-6.

35. Nkenke E, Stelzle F. Clinical outcomes of sinus floor augmentation for implant placement using autogenous bone or bone substitutes: a systematic review. Clin Oral Implants Res 2009;20 Suppl 4:124-33.

36. Froum SJ, Khouly I, Favero G, et al. Effect of maxillary

doi: $10.21037 /$ fomm-21-52

Cite this article as: Romero-Millán J, Aizcorbe-Vicente J, Soto-Peñaloza D, Peñarrocha-Diago $M$, Peñarrocha-Diago $M$, Peñarrocha-Oltra D. Influence of the area of the lateral window upon the radiological parameters and implant success in patients with direct sinus lift after 5-12 years of follow-up. Front Oral Maxillofac Med 2021;3:35. sinus membrane perforation on vital bone formation and implant survival: a retrospective study. J Periodontol 2013;84:1094-9.

37. Lu W, Xu J, Wang HM, et al. Influence of Lateral Windows with Decreased Vertical Height Following Maxillary Sinus Floor Augmentation: A 1-year Clinical and Radiographic Study. Int J Oral Maxillofac Implants 2018;33:661-70. 